\title{
Oxytetracycline residue in Tilapia
}

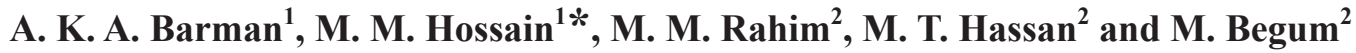 \\ ${ }^{1}$ Department of Fisheries Technology and Quality Control, Sylhet Agricultural University, Bangladesh \\ ${ }^{2}$ Institute of Food science and Technology, Bangladesh Council of Scientific and Industrial Research, Bangladesh
}

\begin{abstract}
The present study was conducted to determine the persistence of oxytetracycline residue in Tilapia (Oreochromis niloticus) available in local fish markets of Sylhet Sadar Upazila. To carry out this experiment, 24 fish samples were randomly collected from four (4) local fish markets under study area from March 2016 to August 2016. Fish samples were analyzed by using High Performance Liquid Chromatography (HPLC) method to detect amount of residues of oxytetracycline. In this study, detectable oxytetracycline residues were observed in five (5) samples of Tilapia ranged between 23.77-39.94 ppb (mean 38.88 $2.99 \mathrm{ppb}$ ). Oxytetracycline residues less than limit of detection were also found in 19 (79.17\%) samples. The detected residues of oxytetracycline in these fish samples did not exceed the maximum residue limit (MRL) $100 \mathrm{ppb}$ recommended by the European Commission. However, long term persistence of high level oxytetracyclines could be a potential hazardous for public health. For this reason supervision of antibiotic uses and monitoring of optimum MRL in Tilapia are utmost needed for farmed fish species.
\end{abstract}

Keywords: Oxytetracycline; Tilapia; Residues; HPLC; MRL

\section{Introduction}

Bangladesh is rich in productive water resources and blessed with diversified fisheries resources (Kibria and Ahmed, 2005). In our country about $63 \%$ animal protein of our meal comes from fisheries resources (Ahmed, 2005). So, fish and fisheries play a dynamic role in meeting up nutritional demand, generating employment, earning foreign currency and uplift the economy of the people of Bangladesh (Alam, 2002). Over the last two decades, aquaculture sector has expanded, diversified and advanced technologically increased trend towards the intensification of cultivation methods in Bangladesh (Ali, 2009; Belton and Azad, 2012; Ali et al., 2013).

Bangladesh has become the fourth largest aquaculture producing country in the world (FAO, 2016) with total fish production 3.68 million metric ton in 2014-2015 and fisheries sector contributed $3.65 \%$ of our GDP, $23.81 \%$ of agricultural sector including valuable foreign currency earning (DoF, 2016). Among the 12 exotic fish species (DoF, 2013) in recent year semi-intensive polyculture of Tilapia (Oreochromis niloticus), intensive polyculture of Thai Pangas (Pangasianodon hypophthalmus) and Thai Koi (Anabas testudineus) in freshwater ponds is also a common scenario in the aquaculture practices of the country (Ali et al., 2016). Over the last three decades, Tilapia (Oreochromis niloticus) production has been significantly developed all over the world and now it is considered as one of the most productive and internationally traded food fish in the world (Frei et al., 2007; Hernández et al., 2013). It is not only the second most important farmed fish globally, next to carps, but is also described as the most important aquaculture species of the 21st century (Shelton, 2002). In Bangladesh, Tilapia is mostly preferred in commercial freshwater ponds aquaculture areas because of its good resistance to poor water quality and disease, tolerance to a wide range of environmental conditions, ability to convert efficiently the organic and domestic waste into high quality protein, rapid growth rate and tasty flavor (Hossain et al., 2005; Siddik et al., 2007). Tilapia farmers reported two major disease problems: red spot disease and mortality caused by parasitic infestations (Ali et al., 2016). So, different types of antibiotics are used to keep healthy fish free from diseases (Avsever et al., 2010). Among them, oxytetracycline is one of the most popular primarily used antibacterial used in aquaculture production (Erdogdu, 2012). Now it is abundantly used in fish farms to treat disease affected fish and/or as a prophylactic in fresh water aquaculture of Bangladesh (Ali et al., 2016). But antibiotics like oxytetracycline have not always been used in a responsible manner in aquaculture (FAO/WHO, 2003). Indiscriminate use of antibiotic could lead to undesirable deposition of their residues in edible tissues which could hamper public health to some extents. Antibiotic residues

\footnotetext{
*Corresponding author e-mail: motaher03@yahoo.com
} 
transferred to humans through food can also alter the intestinal ecology thereby favoring the emergence of resistant microflora (Perrin-Guyomard et al., 2001). Residues of antimicrobials also result in lowering the marketing and export value of aquaculture products (Heuer et al., 2009; Sapkota et al., 2008). So it is important to give attention to this contamination because of the potential hazards associated with these products contained in edible tissues. However, in Bangladesh indiscriminate administrations of oxytetracycline in fish culture have been reported by several authors but quantitative risks assessment of antimicrobial residues in fishes is limited. Preliminary studies have been reported on the monitoring of oxytetracycline residues in cultured fishes emerging from farming systems. Thus present study is aimed to determine the presence of oxytetracycline residues in Tilapia (Oreochromis niloticus) available in local fish markets of Sylhet Sadar Upazila of Bangladesh.

\section{Materials and methods}

\section{Study area and collection of fish samples}

Four (4) fish markets of Sylhet Sadar Upazila were selected for the purpose of collection of fish samples. The selected fish markets were Kazir Bazar, Baluchar Noya Bazar, Mejor Tilah Bazar and Tuker Bazar. Twenty four (24) samples of Tilapia (Oreochromis niloticus) were collected from March 2016 to August 2016. The fish samples were collected individually from the selected fish markets in separate marked polythene bags. Then collected samples were kept in an ice box with sufficient amount of ice. After collection, samples were transported to Microbiology Laboratory of Department of Fisheries Technology and Quality Control, Sylhet Agricultural University, Sylhet and kept in a deep refrigerator. For analyzing purpose, the samples were transported to Food Toxicology Laboratory of Bangladesh Council of Scientific and Industrial Research, Dhaka with icing condition and kept in a deep refrigerator at $-20^{\circ} \mathrm{C}$ for promoting analysis.

\section{HPLC analysis of oxytetracycline residue in fish samples}

\section{HPLC system}

Agilent Liquid chromatography consisting of

i. Agilent : Solvent delivery system series 1100 (Isocratic pump)

ii. Agilent series 1100 Column oven

iii. Agilent 1200 series Fluorescence detector for HPLC

iv. Manual injector capable of injection volumes up to 50 micro liters v. Software : Chem Station Rev A. 10.02

vi. Column: Phenomenex - Gemini 5u C18 110A (250 $4.60 \mathrm{~mm}$ )

\section{Chemicals}

The following chemicals were used. Oxytetracycline hydrochloride (Sigma Aldrich), Methanol - HPLC grade (Merck), Magnesium Acetate (Extra Pure, BDH), Citric Acid - Monohydrate (Merck), Sodium Hydrogen phosphate - anhydrous (Merck), EDTA - disodium dehydrate (Scharlu), Acetic acid (Riedel de Haein), Imidazole (Merck), n-Hexane (Merck), HPLC grade water.

\section{Solution}

The following chemicals were prepared. Mcllvaine Buffer, Mcllvaine Solution: (Mcllvaine Buffer/0.1 M EDTA), Extraction Solution, Imidazole Buffer (1M), Mobile Phase.

\section{Preparation of calibration curve}

Calibration curve was prepared from injecting corresponding concentrations of oxytetracycline standard solutions of $25,50,75,100,125$ and $150 \mathrm{ppb}$. The linear fit curve obtained using, $\mathrm{y}=\mathrm{mx}+\mathrm{b}$;

$$
=0.0132368 x+0.04568
$$

Where, $\mathrm{y}=$ peak area and $\mathrm{x}=$ concentration of oxytetracycline $(\mathrm{ppb})$ and the correlation coefficient $\left(\mathrm{r}^{2}\right)=$ 0.99687. The detection limit for oxytetracycline was 23.62 ppb. The mean retention times (RT) of the oxytetracyclines were found between 4.031 to 4.25 minutes.

\section{Sample preparation and extraction}

After adequate thawing, few grams of muscle sample were collected from fish and minced using chopping board and knife. Then weighed $5.0 \mathrm{~g}$ of partially thawed intact samples was taken separately into $50 \mathrm{~mL}$ polypropylene centrifuge tubes. Then $20 \mathrm{~mL}$ extraction solution was added to each sample and homogenized by using Ultra Turrax until samples were uniformly blended (15- 30 seconds). After rinsing probe with $4 \mathrm{~mL}$ of extraction solution, rinses were added to centrifuge tube. Tubes were capped and shaken 10 minutes on a flatbed shaker at speed. Contents of tubes were centrifuged at a minimum $8000 \mathrm{rpm}$ for 20 minutes at approximately $15^{\circ} \mathrm{C}$. Supernatants were poured into a second centrifuge tube carefully for not allowing any transfer of tissue. Five (5) $\mathrm{mL} \mathrm{n}$-Hexane was added to solution and briefly shaked. Upper layer was removed. A single Whatman \#1 filter paper was placed into a $5.5 \mathrm{~cm}$ Bucher filtering funnel and 
attached to a $250 \mathrm{~mL}$ sidearm flask with vacuum condition. Centrifuge tubes were rinsed with $4 \mathrm{~mL}$ extraction solution and filtered into a flask.An SPE cartridge was attached to an SPE vacuum manifold. The cartridge was conditioned with $10 \mathrm{~mL}$ methanol followed by $15-20 \mathrm{~mL}$ distilled water at approximately $1.5-2.5$ $\mathrm{mL} /$ minute with vacuum as required. The elute were discarded. A $75 \mathrm{~mL}$ reservoir was connected to the cartridge. The filtered sample extracts were added to the SPE reservoir. The flask was rinsed with approximately 4 $\mathrm{mL}$ buffer solution and was added to the rinses to the reservoir. Extract was drained through the column by gravity. The sidearm flask was rinsed with $20 \mathrm{~mL}$ distilled water and added to reservoir. After draining under - 10 $\mathrm{mm} \mathrm{Hg}$ vacuum cartridges were allowed to go dry after the water rinse is completed, and continue to draw air through the cartridge for at least 2 minutes. Then Elute was discarded. A $15 \mathrm{~mL}$ graduated centrifuge tube was placed in the vacuum apparatus to serve as a collection vessel and elute oxytetracycline from the cartridge with 6 mL elution solution. Vacuum condition was applied to initiate flow continue elution. Once flow stops, vacuum applied to remove residual solvent from the cartridge. Tubes were removed from vacuum manifold and vortex was done. The tube containing elute were placed in the sample concentrator at the temperature at $40-50^{\circ} \mathrm{C}$ to reduce volume of the elute to $0.5-0.25 \mathrm{~mL}$ under a stream of dry nitrogen. Final volume was adjusted to $1 \mathrm{~mL}$ with methanol + water $(1: 1)$ and briefly vortexing. Then approximately $1.0 \mathrm{~mL}$ extract were drawn into a $3 \mathrm{~mL}$ syringe and was filtered through a syringe into an HPLC vial $(1.5 \mathrm{~mL})$. The remaining extract was store at $-20^{\circ} \mathrm{C}$.

\section{HPLC parameters for analysis of oxytetracycline residues}

The concentrate extract were subjected to analysis by Agilent 1100 series HPLC system. Mobile phase: Buffer: Methanol = 70:30; Injection volume: $20 \mathrm{~mL}$; Flow rate: 1 $\mathrm{mL} / \mathrm{min}$, Column temperature: $30^{\circ} \mathrm{C}$; Detector: Fluorescence detector (Agilent 1200 series); Excitation wavelength: $380 \mathrm{~nm}$; Emission wavelength: $520 \mathrm{~nm}$ and Run time: 12 minutes.

\section{Recovery evaluation}

The precision of the method was determined as recoveries of oxytetracycline spiked blank samples. For this two replicate oxytetracycline free fish samples were spiked with $150 \mathrm{ppb}$ oxytetracycline standard just before test.

\section{Statistical analysis}

For preliminary processing of raw data obtained from this study was analysed by using the computer software like Microsoft Excel, SPSS etc.

\section{Results and discussion}

Antibiotics are important components in health management of fish farming. Indiscriminate use of antibiotics in fish culture could lead to undesirable deposition of drug residues in edible tissues of fish muscle which could create public health risks to the consumers. On the other hand, fish are considered as bio-indicators of antibiotic contamination in aquatic environments. The aim of this study was to detect the presence of oxytetracycline residues in Tilapa (Oreochromis niloticus). In regards to the data shown in Table-I, detectable amount of oxytetracycline residues were detected in 5 (20.83\%) samples. The range of detected oxytetracycline concentrations of positive samples (Fig.1) were 23.77 to $39.94 \mathrm{ppb}($ mean $=38.88 \pm 2.99 \mathrm{ppb})$. Oxytetracycline residues in $19(79.17 \%)$ samples of Tilapiawere found less than the detection limit under study period.

In present study, only $5(20.83 \%)$ Tilapia fish samples were contaminated with oxytetracycline residues and no samples exceeded the maximum residue limits (MRL) of oxytetracycline (100 ppb) set by European Commission (2010). Fortt et al., (2007) reported presence of oxytetracycline in salmon fish samples caught in farms. Shim et al., (2010) also reported up to $60 \mathrm{ppb}$ of oxytetracycline residues in farmed fish that were collected from their natural habitat. Lower amount of oxytetracycline was also found in Rainbow trout (Oncorhynchus mykiss) meat samples before frying and after frying in in Shahrekord, Iran reported by Sharafati-Chaleshtori et al., (2013). Barani and Fallah (2014) reported tetracyclines residues in rainbow trout muscle. They observed that $63.1 \%$ of the samples contained the residues of tetracyclines where maximum samples contained residues at a range of 1.43 $-91.130 \mathrm{ppb}$ and only one sample (101.40 ppb) exceeds the maximum residue limit of oxytetracycline given by the European Commission. A recent study of Turk and Oguz (2016) observed residues of tetracyclines (oxytetracycline, tetracycline, chlortetracycline, and doxycycline) in 70 fish samples from 70 different fish farms around Muğla province, Turkey. At the end of the analyses, no tetracycline antibiotic residues were found crossing the detection limit. The result complies with some findings of Shim et al., (2010), where they also did not found any oxytetracycline residues in some examined fish species. Baydan et al., (2015) also did not found any oxytetracycline residues in Oblada melanura and Mullus barbatu. Barani and Fallah (2014) reported that tetracycline residues in $36.9 \%$ trout 
Table I. Occurrences and level of oxytetracycline residues in Tilapia

\begin{tabular}{|c|c|c|c|c|c|}
\hline \multirow{2}{*}{$\begin{array}{l}\text { Samples, } \\
\text { (n) }\end{array}$} & \multicolumn{2}{|c|}{ Concentration (ppb) } & \multicolumn{2}{|c|}{ Distribution of Samples, n (\%) } & \multirow{2}{*}{$\begin{array}{c}\text { Exceed } \\
\text { MRL }^{3} \\
\text { n }(\%)\end{array}$} \\
\hline & Mean \pm SEM & Range & $\begin{array}{l}\text { Less than } \\
\text { LOD }^{2}\end{array}$ & $\begin{array}{l}\text { Positive samples } \\
\text { (LOD-100 ppb) }\end{array}$ & \\
\hline 24 & $38.88 \pm 2.99$ & $23.77-39.94$ & $19(79.17)$ & $5(20.83)$ & $0(0.00)$ \\
\hline
\end{tabular}

1Standard Error Mean

2LOD $=$ Limit of detection $=23.62 \mathrm{ppb}$

${ }^{3} \mathrm{MRL}=100 \mathrm{ppb}$

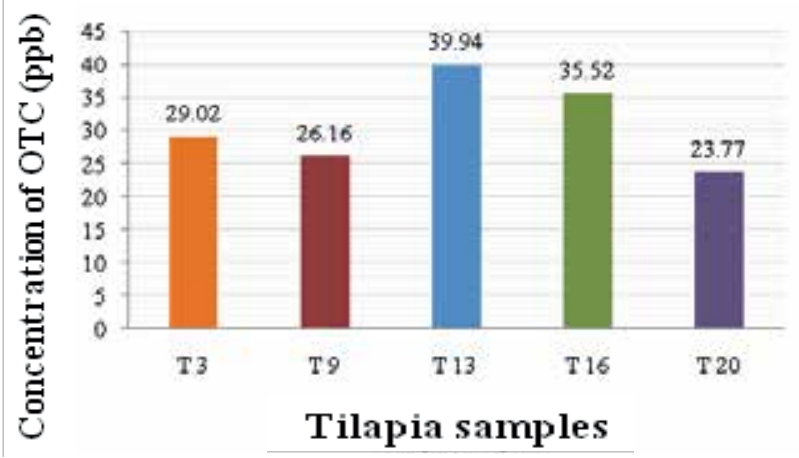

Fig. 1. Detected oxytetracycline residues in Tilapia

samples were less than the detection limit of competitive enzyme-linked immunosorbent assay method. Mahmoudi et al., (2015) also reported $8.44 \pm 6.03 \mathrm{ppb}$ tetracycline residues in Oncorhynchus mykis and confined tetracycline residues were lower than the detection limit of present study. Present study revealed the occurrence of oxytetracycline residues in Tilapia fish having detection levels of oxytetracycline under the maximum residue limit (100 ppb). But their co-occurrence could be hazardous for public health in case of higher concentrations with long term exposure. Therefore supervision of antibiotics uses in fish farming at farmer's level is needed with residue monitoring and food safety training of producers and consumers.

\section{Conclusion}

From the results and findings obtained in the present investigation it can be concluded that small portion of Tilapia (Oreochromis niloticus) available in local fish markets of Sylhet Sadar Upazila are contaminated with oxytetracycline residues. It is a positive sign that in most samples oxytetracycline residues were below the detection limit and detected oxytetracycline residues in the positive samples did not exceed the maximum residue limit recommended by the European Commission. However, some remedial and precaution measures are also necessary to ensure disease free fish for public health safety. Oxytetracycline and other antibiotics should only be used for treatment of fishes in prescribed doses. The withdrawal period of antibiotics should be taken into consideration before marketing of fish. Awareness build up programs and regular residue monitoring of marketed fish should be performed by government authorities such as Department of Fisheries, Fish Inspection and Quality Control etc. Finally investigation on antibiotic resistance bacteria in the intestine of fish and sediments of farming areas and antibiotics residue monitoring study on other species of fishes are utmost needed.

\section{References}

Ahmed MNU (2005), Fisheries sector in the economy of Bangladesh and its potential development (Published in Bengali) In: Souvenir of National Fish Fortnight (Matsya Pokkhya) 2005, Department of Fisheries, Dhaka, Bangladesh, pp 11-15.

Alam MF (2002), Socioeconomic aspects of carp production and consumption in Bangladesh. pp 83-93. In: Penman DJ, Hussain MG, McAndrew BJ and Mazid MA (eds), Proceedings of a workshop on Genetic Management and Improvement Strategies for Exotic Carps in Asia. Dhaka, Bangladesh. Bangladesh Fisheries Research Institute, Mymensingh, Bangladesh. p 83.

Ali H, Haque MM and Belton B (2013), Striped catfish (Pangasianodon hypophthalmus, Sauvage, 1878) aquaculture in Bangladesh: an overview, Aquaculture Research 44(6): 950-965.

Ali H, Rico A, Murshed-e-Jahan K and Belton B (2016), An assessment of chemical and biological product use in aquaculture in Bangladesh, Aquaculture 454: 199-209.

Ali H (2009), Assessment of stakeholders' perceptions on Pangasius Aquaculture Dialogue (PAD) standards in two villages, Mymensingh, Bangladesh, MS Thesis, Dept. of Aquaculture, Bangladesh Agricultural University, Mymensingh, p 52. 
Avsever ML, Türk N and Tunaligil S (2010), The increase of antibiotic resistance in aquaculture and its effects on human health, Bornova Veteriner Kontrolve Araştirma Enstitüsü, 32(46): 19-23.

Barani A and Fallah AA (2014), Occurrence of tetracyclines, sulfonamides, fluoroquinolones and florfenicol in farmed rainbow trout in Iran, Food and Agricultural Immunology 26(3): 420-429.

Baydan E, Kaya S, Çagirgan H, Yildirim E, Altintas L, Yurdakok B, Ekici H, Aydin FG and Kucukosmanoglu AG (2015), Investigation of some veterinary drug residues in sea water, sediment, and wild fishes captured around fish farms in the Aegean sea: Oxytetracyline, ivermectin and emamectin, Ankara Üniversitesi Veteriner Fakültesi Dergisi, 62(3): 171-176.

Belton, B and AzadA (2012), The characteristics and status of pond aquaculture in Bangladesh, Aquaculture, 358: $196-204$.

DoF (Department of Fisheries) 2016, National Fish Week 2016 Compendiun (In Bengali), Department of Fisheries, Ministry of Fisheries and Livestock, Bangladesh, p 148.

DoF (Department of Fisheries) 2013, National Fish Week 2013 Compendiun (In Bengali), Department of Fisheries, Ministry of Fisheries and Livestock, Bangladesh, p 130.

Erdogdu AT (2012), Using antibiotics in aquatic living beings, Rational use of antibiotics and antimicrobial resistance symposium, Ankara, Turkey, pp 87-95.

European Commission (2010), Commission Regulation (EU) No. 37/2010 of 22 December 2009 on pharmacologically active substances and their classification regarding maximum residue limits in foodstuffs of animal origin, Official Journal of the European Union, L15, pp1-72.

FAO (Food and Agriculture Organization) 2016, The State of World Fisheries and Aquaculture 2016, Contributing to food security and nutrition for all. Rome, p 200.

FAO/WHO (2003), Code of Practice for Fish and Fishery Products. Codex Alimentarius Commission. CAC/RCP. 52-2003, Rev. 2-2005, p 242.

Fortt ZA, Cabello CF and Buschmann RA (2007), Residues of tetracycline and quinolones in wild fish living around a salmon aquaculture center in Chile,
Revistachilena de infectologia: organooficial de la Sociedad Chilena de Infectologia 24(1): 14-18.

Frei M, Razzak MA, Hossain MM, Oehme M, Dewan S and Becker K (2007), Performance of common carp, Cyprinus carpio L. and Nile tilapia, Oreochromis niloticus (L.) in integrated rice-fish culture in Bangladesh, Aquaculture 262(2): 250-259.

Heuer OE, Kruse H, Grave K, Collignon P, Karunasagar I and Angulo FJ (2009), Human health consequences of use of antimicrobial agents in aquaculture, Clinical Infectious Diseases 49(8): 1248-1253.

Hernández M, Gasca-Leyva E and Milstein A (2013), Polyculture of mixed-sex and male population of Nile tilapia (Oreochromis niloticus) with the Mayan cichlid (Cichlasoma urophthalmus), Aquaculture 418: $2-31$.

Hossain MA, Hossain AA and Sultana N (2005), Over-wintering growth of normal and monosex GIFT Tilapia, Oreochromis niloticus in Bangladesh fed on formulated diet, Journal of Aquaculture in the Tropics 20: 271-286.

Kibria MG and Ahmed KKU (2005), Diversity of selective and non-selective fishing gear and their impact on inland fisheries in Bangladesh, Naga World Fish Center Quarterly 28(1-2): 43-48.

Mahmoudi R, Gajarbeygi P, Norian R and Farhoodi K (2015), Chloramphenicol, sulfonamide and tetracycline residues in cultured rainbow trout meat (Oncorhynchus mykiss), Bulgarian Journal of Veterinary Medicine 17(2): 147-152.

Perrin-Guyomard A, Cottin S, Corpet DE, Boisseau J and Poul JM (2001), Evaluation of residual and therapeutic doses of tetracycline in the human-flora-associated (HFA) mice model, Regulatory Toxicology and Pharmacology 34(2): 125-136.

Sapkota A, Sapkota AR, Kucharski M, Burke J, McKenzie S, Walker P and Lawrence R (2008), Aquaculture practices and potential human health risks: current knowledge and future priorities, Environment International 34(8): 1215-1226.

Sharafati-Chaleshtori R, Mardani G, Rafieian-Kopaei M, Sharafati- Chaleshtori A and DreesF (2013), Residues of Oxytetracycline in Cultured Rainbow Trout, Pakistan Journal of Biological Science 16(21): 1419-1422. 
Shelton WL (2002), Tilapia culture in the $21^{\text {st }}$ century. In: Guerrero, Eds. RD III and Guerrero-del Castillo MR, Proceedings of the International Forum on Tilapia Farming in the $21^{\text {st }}$ Century, Philippine Fisheries Association Inc. Los, Banos, Laguna, Philippines, p 184.

Shim KB, Mok JS, Jo MR, Kim PH, Lee TS, Kim JH and Cho YJ (2010), Residues of Antibiotics in Wild and Cultured Fishes Collected from Coast of Korea, Korean Journal of Fisheries and Aquatic Sciences 43(1): 12-17.
Siddik MAB, Khan MMR and Hasan M (2007), Evaluation of different diets on the growth of normal and monosex GIFT tilapia (Oreochromis niloticus L.) in Bangladesh, Journal of Bangladesh Agrilcultural University 5: 377-384.

Turk E and Oguz H (2016), Investigation of tetracycline residues in fish caught from surrounding fish farms in Muğla district, Eurasian Journal of Veterinary Sciences 32(2): 74-79. 